\title{
Insolation and disturbance history drive biocrust biodiversity in Western Montana rangelands
}

\author{
Rebecca A. Durham (iD • Kyle D. Doherty • Anita J. Antoninka • Philip W. Ramsey • \\ Matthew A. Bowker
}

Received: 7 February 2018 / Accepted: 14 June 2018 / Published online: 26 June 2018

(C) The Author(s) 2018

\begin{abstract}
Background and Aims Biological soil crust (biocrust) communities, though common and important in the intermountain west, have received little research attention. There are gaps in understanding what influences biocrust species' abundance and distributions in this ecoregion. Climatic, edaphic, topographic, and biotic forces, in addition to anthropogenic disturbance can all influence the biocrust.

Methods We determined the relative influence of several possible environmental filters in biocrust communities of western Montana (USA) grasslands at two spatial scales. The larger scale exploited strong topographically-dictated climatic variation across $>60 \mathrm{~km}^{2}$, while the smaller scale focused on differences among distinct microsites within $\sim 700 \mathrm{~m}^{2}$ plots.

Results We detected a total of 96 biocrust taxa, mostly lichens. Biocrust richness at each site ranged from 0 to 39 species, averaging 14 species. Insolation, aspect, and disturbance history were the strongest predictors of
\end{abstract}

Responsible Editor: Honghua He.

Electronic supplementary material The online version of this article (https://doi.org/10.1007/s11104-018-3725-3) contains supplementary material, which is available to authorized users.

R. A. Durham $(\bowtie) \cdot$ P. W. Ramsey

MPG Ranch, 1001 S. Higgins Ave STE A3, Missoula, MT 59801, USA

e-mail: rdurham@mpgranch.com

K. D. Doherty · A. J. Antoninka · M. A. Bowker

School of Forestry, Northern Arizona University, 200 E. Pine

Knoll Drive, Box 15018, Flagstaff, AZ 86011, USA biocrust richness, abundance, and species turnover across the landscape; soil texture was influential for some biocrust community properties. Steep, northfacing slopes that receive longer periods of shade harbored higher diversity and cover of biocrust than southfacing sites. At a small scale, interspaces among native herbaceous communities supported the greatest diversity of biocrust species, but microsites under shrub canopies supported the greatest cover.

Conclusions We found that, among the variables investigated, tillage, insolation, soil texture and the associated vegetation community were the most important drivers of biocrust abundance and species richness. This study can inform the practice of restoration and conservation, and also guide future work to improve predictions of biocrust properties.

Keywords Biocrust $\cdot$ Lichens $\cdot$ Bryophytes . Terricolous $\cdot$ Montana $\cdot$ Community analysis

\section{Introduction}

Climatic, edaphic, topographic, and biotic forces, in addition to anthropogenic disturbance can all influence species' natural abundance and distributions. The range of tolerable environmental conditions and resource availabilities were conceived as the n-dimensions of the Hutchinsonian niche (Hutchinson 1957). Since the development of that concept, the environment has often been metaphorically envisioned as one "filter" along with dispersal and biotic filters which permits some 
members of the regional species pool to establish and persist in a community while excluding others (Zobel 1997; Kraft et al. 2015). These concepts have permeated plant and animal ecology, but are less commonly investigated in biological soil crusts (biocrusts). Biocrusts are assemblages of lichens, bryophytes, algae, cyanobacteria, fungi, and microfauna that form on and stabilize dryland soil surfaces (reviewed by Belnap and Lange 2003; Rosentreter et al. 2016; Seppelt et al. 2016). One way in which biocrusts are different from plant and animal communities is that they may not be strongly dispersal-limited due to the existence of small propagules such as spores that can plausibly disperse across long distances, even continent to continent (Muñoz et al. 2004; McDaniel and Shaw 2005). Consequently, there are multiple biocrust species that have multi-continental distributions or broad ranges within a single continent. We might expect that at continental and smaller scales, environmental characteristics, such as climate, insolation and edaphic conditions, constitute the initial filter determining where species occur (Bowker et al. 2016, 2017).

Recent synthesis has pointed out a need for a better understanding of not only how biocrusts respond to variation in their environment, but also how these responses vary with spatial scale (Ferrenberg et al. 2017a, b). There is no universal model of biocrust distribution applicable to every study area. It has been posited, but not extensively tested, that the relative importance of climatic and edaphic influences at large ecoregional scales depends on the degree of variability of those factors in the study area (Bowker et al. 2016). Further complicating the matter, specific expressions of interdependent climatic, edaphic, topographic, and biotic forces vary by spatial scale (Ochoa-Hueso et al. 2011; Bowker et al. 2016). For example, water availability may correlate with biocrust abundance, composition and physical structure across regional precipitation and evapotranspiration gradients, local insolation gradients generated by topography, or fine-scale shade gradients generated by plant canopies and soil surface microtopography (Bowker et al. 2006). Juxtaposed over the complex, scale-dependent environmental influences on biocrust communities are anthropogenic disturbance legacies.

The aim of this study was to identify patterns of abundance and community structure of biocrust lichens, mosses, and liverworts attributable to environmental conditions and disturbance legacies with the eventual goals of: identifying suitable community assemblages for use in restoration, establishing reasonable targets for restoration efforts, and locating biocrust conservation priority areas. Our study system is a large private ranch that supported crops and livestock in the past, and is currently managed for conservation goals with an active ecological restoration program. Biocrusts are potential objects of conservation and agents of restoration in this and other systems because of their many contributions to ecosystem function. Biocrusts protect soil from erosion, fix carbon and nitrogen, moderate temperatures, and influence hydrology and plant growth (Bowker et al. 2011; Delgado-Baquerizo et al. 2013; Rodríguez-Caballero et al. 2015; Zaady et al. 2003). Biocrusts are nearly universally sensitive to livestock trampling or other compressive forces, tillage, land surface conversions, and other physical disturbances (Belnap and Lange 2003; Zaady et al. 2016). Recovery of initial biomass and diversity after such disturbances may require multiple decades, thus imprinting long-term influence on biocrust distribution patterns and thus ecosystem function (Weber et al. 2016).

We documented biocrust community composition and abundance across multiple biotic and abiotic gradients and land use histories at two spatial scales. The larger scale exploited strong topographically-dictated climatic variation across $>60 \mathrm{~km}^{2}$, while the smaller scale focused on differences among distinct microsites within $\sim 700 \mathrm{~m}^{2}$ plots. These two scales can help inform biocrust management and conservation by teasing apart what drives biocrust community variability within a site vs. across a landscape. Because of low variation in edaphic physical and chemical properties, relative to topographic complexity, we hypothesized that topographically-derived factors such as insolation and topographic wetness would drive biocrust abundance, diversity, and species turnover. We expected a strong legacy of disturbance history to dampen environmental influences by generating low abundance and diversity and a reduced, nested set of community members. We investigated the large-scale hypotheses using a combination of random forest and ordination techniques, generating maps of predicted biocrust distribution patterns. We expected that distribution patterns at the smaller scale would also differ based on the type of vascular plant overstory and disturbances, and that at both scales similar underlying mechanisms would drive patterns. We hope that our approach of assessing biocrust community properties at two potentially relevant scales will improve management outcomes for this poorly protected group. 


\section{Materials and methods}

Study site

This study was conducted in the Sapphire Range of western Montana on MPG Ranch. MPG Ranch is a 3800-ha conservation property with topography that varies from flat bottomland to gentle foothills and forested mountain slopes. The landscape is typical of the intermountain valley region. It consists of agricultural land, sagebrush steppe, riparian forests, dry open forests, and moist mixed coniferous forests. Based on modeled thirty-year climate norms, mean annual temperature is $7.6{ }^{\circ} \mathrm{C}$ and mean annual precipitation is $327 \mathrm{~mm}$, although there is substantial variation dependent on elevation (Hijmans et al. 2005). Climate typically follows a pattern of cold moist winters, when most precipitation occurs, and hot, dry summers. Soil temperature and recent weather data can be accessed from this website: http://livecams.mpgranch.com.

Agricultural activities occurred on $\sim 728$ ha of former sagebrush steppe and grasslands from the 1870's until 2007, including open and closed cattle and sheep range, wheat production, and tilled conversion to forage grasses. The exotic grasses, selected for summer forage production, were mainly intermediate wheatgrass varieties (Thinopyrum intermedium) and crested wheatgrass (Agropyron cristatum). Agricultural areas were maintained as near monocultures by frequent herbicide applications, mainly picloram. Cheatgrass (Bromus tectorum), spotted knapweed (Centaurea stoebe), and leafy spurge (Euphorbia esula) are among the common invasive species. Ranching ceased in 2007 when the land was purchased by the current owner. Efforts to restore native prairies on the old fields started in 2010 and are ongoing (restorationmap.mpgranch.com).

\section{Field sampling}

Ninety-eight biocrust survey sites were selected as a random subset of the 500 permanent monitoring sites on the ranch that fell within potential crust habitat in the lower to upper montane rangeland (Fig. 1). Sites were located in the sagebrush steppe shrubland, native grassland, or in former sage steppe areas that were converted to agriculture. Sites represented a variety of topographic settings, ranging from flat lowlands to ridge tops and slopes. We selected this subset to maximize variation in elevation, major vegetation community, and insolation.
This was initially accomplished by binning sites into elevation quartiles, further binning each quartile into major vegetation types (those represented by 5 or more samples), and within each bin selecting a plot receiving relatively high and low insolation, and 1-2 intermediates. After the first season of sampling, this selection process was refined by using k-means clustering of elevation, slope, and insolation to identify gaps in sampling efforts along these gradients (Doherty et al. 2017). These strategies were augmented by the inclusion of "intuitive" plots that surveyors selected subjectively to capture unique habitats or unique elements of the biocrust flora. Intuitive plots accounted for $\sim 18 \%$ of samples. The study area was variable in topography and dominated by sagebrush, bitterbrush, rough fescue, Idaho fescue, and native and exotic forbs. We avoided forests and riparian areas. Site elevation ranged from $1045 \mathrm{~m}$ to $1544 \mathrm{~m}$.

Each plot had a radius of $15 \mathrm{~m}$ positioned along the dominant aspect, and encompassed an area of $707 \mathrm{~m}^{2}$. We collected percent cover and species composition for bryophytes and lichens, and also used these data to estimate species richness as the number of detected species. Within each plot, we conducted a two-scale survey of the whole plot, as well as major microsites. Microsites included native grass-forb interspace, beneath shrub canopy, and agricultural grass-forb interspace. Data collection occurred at a minimum of five $0.0625 \mathrm{~m}^{2}$ randomly located quadrats per microsite, and included biocrust cover per species, ground cover, canopy cover, and native and exotic vascular plant cover data by functional group. These data were paired with a line intercept transect bisecting the site parallel to the slope, along which we measured the abundance of the major microsite types. These relative abundances allowed us to use micrositelevel data to estimate cover of all species at the whole-site scale using weighted averaging. These surveys were followed by a 10-min search for biocrust species that were not captured within the quadrats. Species not fieldidentifiable were collected and identified based on morphological and chemical characteristics in the laboratory.

We also collected soils at each site to determine $\mathrm{pH}$ and soil texture. For each composite sample we troweled 5 soil collections along each transect at regular intervals to a depth of $\sim 4 \mathrm{~cm}$ and homogenized them.

\section{Environmental data}

In the laboratory, we subsampled $2 \mathrm{~g}$ of air-dried soil from our composite soil sample and mixed it with $\sim 4 \mathrm{ml}$ 


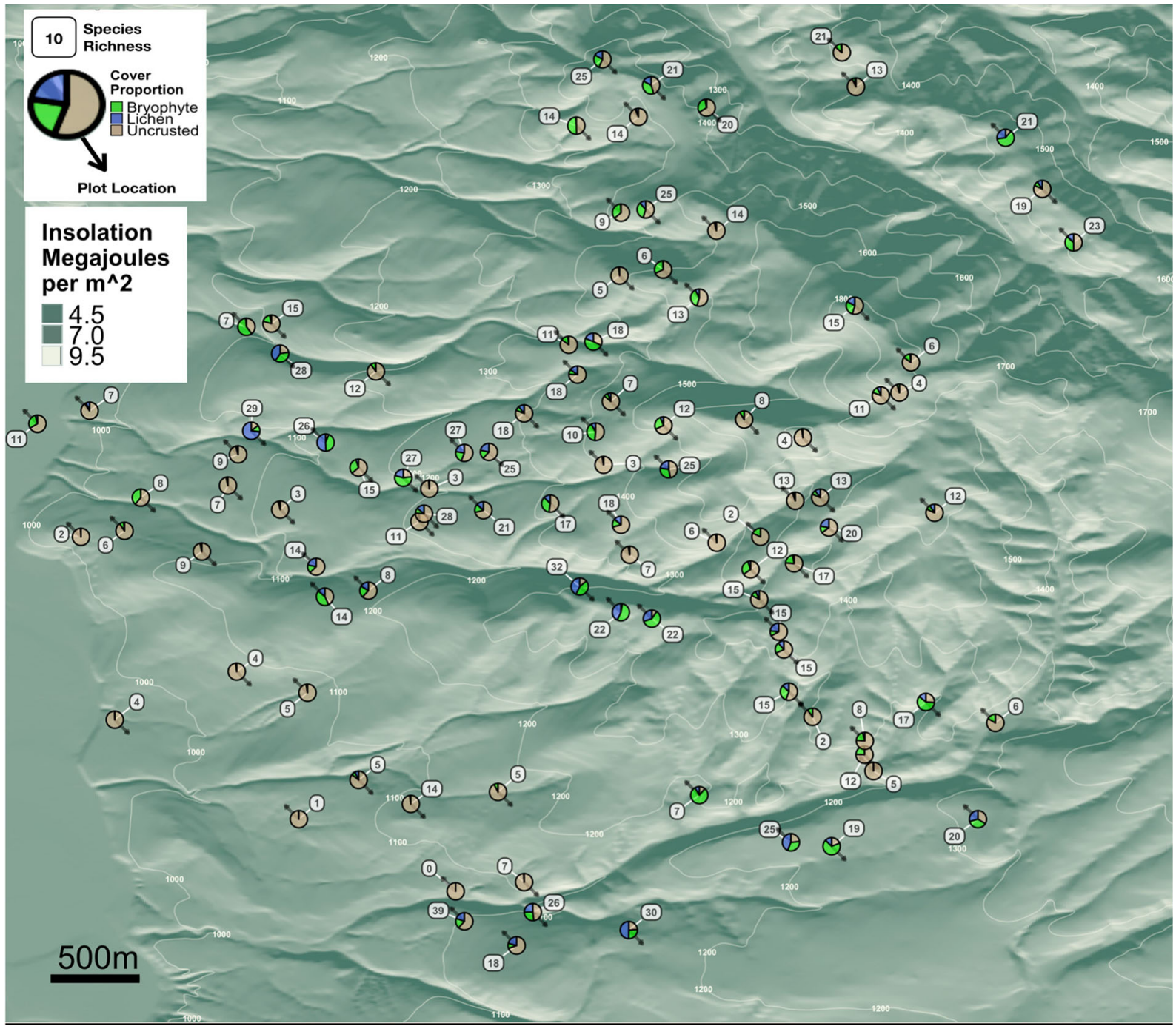

Fig. 1 Survey locations across MPG Ranch. Pie charts depict proportion of bryophyte, lichen, and uncrusted cover types. Numbers in white bubbles, adjacent to pie charts, indicate species richness. The background color gradient depicts the total insolation received during the daylight hours of the winter solstice (minimum insolation) across the surveyed area
$0.1 \mathrm{M} \mathrm{CaCl}_{2}$ solution until saturated. The mixture was allowed to stand for $30 \mathrm{~min}$ before measuring with a calibrated $\mathrm{pH}$ meter (Rayment and Higginson 1992). We subsampled $\sim 50 \mathrm{~g}$ of air-dried soil for soil texture analysis. Because soils were high in organic matter, we used a pretreatment with hydrogen peroxide, in which soils were mixed 1:1 with deionized water, heated to $65{ }^{\circ} \mathrm{C}$, and $30 \% \mathrm{H}_{2} \mathrm{O}_{2}$ was added incrementally until bubbling subsided. Soils were then dried $\left(60^{\circ} \mathrm{C}\right)$ and weighed for soil texture analysis via a modified Bouyoucos hydrometer method (Gee and Bauder 1986).

In addition to empirical soil measurements, we assembled a set of topographic data layers (Table 1), calculated from the National Elevation Dataset (Gesch et al. 2002). Topographic position indices, TPI, indicate the mean difference in elevation of a focal pixel in relation to a radius of surrounding pixels. We generated TPI at three scales: 10,100 , and $1000 \mathrm{~m}$ radii. To incorporate information on aspect, we calculated eastness and northness, as described in Wilson et al. (2007). We determined the sum of direct and indirect insolation, accounting for viewshed, integrated over the periods of daylight during the summer and winter solstices, which we refer to as maximum and minimum insolation, respectively (Corripio 2014, insol package). To incorporate information regarding water accumulation as a function of topography, we calculated 
Table 1 Environmental variables considered in our analyses. We report the mean values of each in bold, with the ranges reported in parentheses. All soil properties were determined empirically.
Terrain variables were derived from digital elevation models (Gesch et al. 2002). Past tillage was determined in previous survey efforts

$\begin{array}{ll}\text { Mean and Range } & \text { Units } \\ \mathbf{5 . 6 4}(4.37 \text { to } 7.30) & \text { None } \\ \mathbf{0 . 5 5}(0.28 \text { to } 0.82) & \text { Percent } \\ \mathbf{0 . 1 1}(0.00 \text { to } 0.31) & \text { Percent } \\ \mathbf{0 . 3 4}(0.15 \text { to } 0.54) & \text { Percent } \\ & \\ \mathbf{1 3 1 3}(966 \text { to } 1831) & \text { Meters } \\ \mathbf{1 6 . 0 4}(0.71 \text { to } 44.60) & \text { Degrees } \\ \mathbf{- 0 . 4 2}(-1.00 \text { to } 0.99) & \text { None } \\ \mathbf{- 0 . 0 3}(-1.00 \text { to } 1.00) & \text { None } \\ \mathbf{3 . 0 5 e} 7(2.53 \mathrm{e} 7 \text { to } 3.18 \mathrm{e} 7) & \text { Joules } / \mathrm{m}^{2} \\ \mathbf{6 . 1 3 e 6}(2.90 \mathrm{e} 6 \text { to } 1.07 \mathrm{e} 7) & \text { Joules } / \mathrm{m}^{2} \\ \mathbf{0 . 1 2}(-2.03 \text { to } 2.26) & \text { None } \\ \mathbf{1 . 4 3}(-16.93 \text { to } 14.96) & \text { None } \\ \mathbf{1 3 . 4 1}(-64.53 \text { to } 150.69) & \text { None } \\ \mathbf{3 . 3 6}(2.01 \text { to } 6.78) & \text { None } \\ 0.26 & \\ & \end{array}$

*radius of calculation

the SAGA wetness index, which is a unit-less measure indicating the relative amount of water that drains into a pixel from upslope areas (Boehner et al. 2002). We derived the above variables using a combination of raster and insol packages in R, Google Earth Engine, and SAGA GIS. Past survey efforts recorded historic land use, and we also included past tillage as a predictor as well.

We selected these variables with the goal of capturing the breadth of environmental information available that might impact biocrust community composition. While most of these variables contribute unique information, insolation and northness were strongly correlated, as were sand and silt percentages (Pearson's Correlation coefficients $>|0.7|)$. We felt that, in spite of these correlations, each still added some unique information that could improve model performance, and we included them in the model.

Data analysis

\section{Differences in biocrust communities among microsite types}

Simple comparisons of cover and common diversity indices at the microsite scale were done using one
way-ANOVA in SPS JMP 13.0 after testing assumptions of normality and homogeneity of variance. We used Tukey's HSD to test for post hoc differences among groups. We tested differences among biocrust communities by microsite type using multi-response permutation procedures with Bray-Curtis distance, which assesses between and within group variance in PC-ORD 6.0 (MJM Software Design; Biondini et al. 1985). Also in PC-ORD. We used indicator species analysis to determine which biocrust species were associated with a particular habitat type (Dufrene and Legendre 1997).

\section{Determining environmental drivers of biocrust community structure}

We used an ordination-based approach to determine the degree to which our environmental predictors correlated with community composition (here defined as the identity and relative abundance of species) of lichen and bryophyte-dominated biocrusts (Bowker et al. 2011). We created a non-metric multidimensional scaling (NMDS; Kruskal 1964) ordination of the biocrust community matrix, using Bray- Curtis distance. Prior to ordination, we modified the community matrix such 
that: 1. Species occurring in fewer than two samples were omitted ( 22 species omitted) because such species cannot be reliably placed in ordination space and create noise, 2. All species were relativized to a common scale from 0 to 1 , to ensure that the ordination represented variation in abundance of all species rather than only a few dominants. We used the "slow \& thorough" autopilot mode in PC-Ord 6 (MJM Software Design), determining dimensionality using a Monte Carlo tests, which resulted in a three dimensional ordination (final stress $=$ 13.2, cumulative $\mathrm{R}^{2}=0.57$ ).

A NMDS ordination can be rotated in any direction without altering the spatial proximity of the points relative to one another. Information from a second data matrix containing our environmental predictors was overlaid in this ordination space by creating a joint biplot, wherein vectors represent the correlation of variables from the second matrix to axes of the lichenbryophyte ordination. An NMDS ordination may be rotated in any dimension without altering the distance between points. In doing so, new axes are created which may be more or less correlated with an environmental predictor. To determine the strongest correlation of a given environmental predictor with community composition, we iteratively rotated the lichen-bryophyte ordination to realign the first axis of the ordination so that it parallels the functional vector being considered, and obtained the Pearson correlation coefficient of the environmental vector and the axis (McCune and Grace 2002). This exercise was repeated for all environmental predictors to identify which of the predictors was the strongest.

Finally, to determine how various species responded to environmental gradients, we rotated our ordination based upon the single strongest environmental correlate, minimal insolation. This rotation also nearly maximized maximal insolation, past tillage, and northness on axis 1 , and was well correlated with soil texture on axis 3 . There were no strong environmental correlates with axis 2 , though soil $\mathrm{pH}$ was moderately negatively correlated. Using this most informative rotation, we obtained the correlations of all species with all axes.

To further explore the environmental drivers of biocrust species richness and abundance we used the machine learning algorithm, random forest. Random forests are built from an ensemble of decision trees, each trained on a random subset of observations and predictors (Breiman 2001; Friedman et al. 2001). Conveniently, random forest has a built-in cross validation strategy, and provides an unbiased estimate of model error in its default setting (out-ofbag error, Breiman 2001; Cutler et al. 2007). We applied this algorithm to our survey data to produce four separate models predicting: 1) bryophyte cover, 2) bryophyte richness, 3) lichen cover, and 4) lichen richness as a function of our environmental variables (Table 1). From these models, we extracted variable importance metrics, or the percent increase in mean squared (out-of-bag) error when a variable in question is left out of the model, and partial dependence plots for the environmental drivers using the randomForest and mlr packages in $\mathrm{R}$. To ensure stability of model error and importance metrics, we set the number of trees in each model to 5000, and left all other tuning parameters in the default setting. Among correlated variables, such as insolation and northness, we expected variable importance values to be, more or less, equally divided and underestimated when compared to uncorrelated variables (Genuer et al. 2010). To evaluate model performance we calculated the mean squared error (MSE) and pseudo $\mathrm{R}^{2}$ (1 - MSE / Variance (y)) from the out-of-bag samples.

Predictive mapping of biocrust community properties

Following model training, we predicted species cover and richness metrics across the areas of MPG Ranch with our random forest models. Data for these predictions came from our derived terrain and land use layers (Table 1), and soil layers generated by the following method. Because there were no soil layers for the study area to match the $10 \mathrm{~m}$ resolution of the terrain variables, we generated ensemble models from three data sources: 1) kriged empirical soil survey data, where semi-variograms were fit with the automap package in $\mathrm{R}, 2$ ) rasterized SSURGO polygons, assigning tabulated data for $\mathrm{pH}$ and texture to corresponding pixels with the raster package in $\mathrm{R}$ (Soil Survey Staff, United States Natural Resources Conservation Service n.d), and 3) Soil Grids $100 \mathrm{~m}$ data resampled via bilinear interpolation to match the terrain data layer resolution (Ramcharan et al. 2017). We calculated an equally weighted mean of these three sources to produce our ensemble soil models of $\mathrm{pH}$ and texture for the areas of MPG Ranch (Supplemental Fig. 1, Supplemental Table 1 in Online Resource 1). 


\section{Results}

Biocrust community diversity and abundance

We detected a total of 96 biocrust species or species groups at the 98 sites sampled, 72 lichens and 24 bryophytes (Table 2). Richness ranged from 0 species to 39 species per site with an average of 14 (Fig. 1). Biocrust cover ranged from 0 to $97 \%$ with an average of $31 \%$ $[\mathrm{SD} \pm 27 \%]$. Bryophyte and lichen species cumulative cover and frequency calculations revealed 7 bryophytes and 6 lichens species or genera that were most frequently encountered and/or make up high proportion of cumulative cover (Table 2). Common bryophytes included Syntrichia ruralis, Bryum argenteum, Gemmabryum caespiticium, Cephaloziella divaricata, Homalothecium aureum, and Polytrichum juniperinum. Common lichens included Cladonia spp., Peltigera spp., Leptogium spp., Buellia spp., and Caloplaca jungermanniae. Together Cladonia spp. and Syntrichia ruralis accounted for $63 \%$ of the cumulative biocrust cover across study points. We encountered 21 lichens and 3 bryophytes only once. Species accumulation analysis suggests that we captured the majority of the species in this area (96 species observed, $\mathrm{Chao}^{2}=114$ species predicted).

\section{Community differences among microsites}

Biocrust communities were different among all microsites $(\mathrm{A}=0.1, p<0.0001)$, and indicator species emerged for all of the microsite types except for the agricultural grasslands (Table 2). Biocrust cover differed between the three major microsites (Fig. 2). Biocrust cover in native grass-forb interspaces averaged 33\%, beneath shrubs $42 \%$, and agricultural grass-forb interspaces $6 \%$. Native dominated microsites had different cover ratios of bryophytes and lichens (Fig. 2), with bryophyte cover greater than lichen cover $\sim 2: 1$ for native grass/forb interspaces, and $\sim 4: 1$ beneath shrubs. Agricultural grass-forb habitat had an approximately equal bryophyte:lichen ratio.

Likewise, richness varied among microsites (Fig. 2). Overall, agricultural grass-forb interspaces had lower richness than the other two microsite types, but shrub canopy interspaces had the lowest evenness and diversity (Fig. 2). For lichens, species richness was greater in the native grass-forb interspaces compared to the agricultural grass-forb interspaces (Fig. 2). For bryophytes, the agricultural grass-forb interspaces had higher richness than the two native microsite types, but the native and agricultural grass-forb interspaces had greater evenness and diversity than the shrub canopies (Fig. 2).

Community differences along environmental gradients

Our final NMDS ordination was 3 dimensional, and captured approximately $57 \%$ of the variation in distances among samples (final stress 13.2, instability $<0.0001 \%$ ). The strongest environmental correlate with the ordination was minimum insolation $(r=-0.54$; Supplemental Table 2 in Online Resource 1). Using this variable as a basis for rotation, we found strong support for an axis related to both winter and summer insolation (positive correlates) and northness (negative correlate), but also past tillage (positive correlate; Supplemental Table 2 in Online Resource 1). Nearly all species in the community were negatively correlated with this axis, many moderately or strongly so, indicating that most species were more abundant in north-facing, low insolation, or untilled environments (Fig. 3, Supplemental Table 3 in Online Resource 1). Despite this broad preference across the community for low insolation, some species had stronger, clearer preferences for low insolation or untilled habitats, including Syntrichia ruralis and Cladonia spp. (Fig. 4). A second axis was best correlated positively to $\mathrm{pH}$ and TPI at $100 \mathrm{~m}$ (Supplemental Table 2 in Online Resource 1). Few species correlated strongly with this axis, but those that did demonstrated mixed (both positive and negative correlations) preference for insolation and tillage (Supplemental Table 3 in Online Resource 1). We found that a third ordination axis correlated positively to $\%$ sand, elevation, and TPI at $1000 \mathrm{~m}$ (Supplemental Table 2 in Online Resource 1). Again, species were correlated variously with this axis; correlations ranged from moderately positive to moderately negative with most species not clearly associated with either pole (Fig. 3, Supplemental Table 3 in Online Resource 1).

\section{Biocrust cover along environmental gradients}

Our models explained about one third of the variance in both lichen (Table 3, pseudo $R^{2}=0.33$, Mean Squared Error $=123.62)$ and bryophyte cover (Table 3, pseudo $R^{2}=0.33$, Mean Squared Error = 228.88). We found that percent sand content, minimum insolation and northness variables were the 
Table 2 Frequency and mean relative abundance of each taxon in each microsite from quadrat data. Frequency reported as percentage of plots in given group where given species is present. Relative abundance is average abundance of a given species in a given group of plots/over the average abundance in all plots expressed as a percent. Species in bold are associated with the bolded microsite based on indicator species analysis

\begin{tabular}{|c|c|c|c|c|c|c|c|c|}
\hline \multirow[t]{2}{*}{ Taxon } & \multirow{2}{*}{$\begin{array}{l}\text { Tax. } \\
\text { Group }\end{array}$} & \multirow{2}{*}{$\begin{array}{l}\text { Code } \\
\text { (Fig. 2) }\end{array}$} & \multicolumn{3}{|c|}{ Frequency } & \multicolumn{3}{|c|}{ Mean relative abundance } \\
\hline & & & AGFI & GFI & $\mathrm{SHC}$ & AGFI & GFI & $\mathrm{SHC}$ \\
\hline Acarospora schleicheri & AcaSch & $\mathrm{L}$ & 0 & 0 & 0 & 0 & 0 & 0 \\
\hline Arthonia glebosa & ArtGle & $\mathrm{L}$ & 0 & 9 & 8 & 0 & 62 & 38 \\
\hline Aspicilia reptans & AspRep & $\mathrm{L}$ & 6 & 2 & 3 & 14 & 6 & 80 \\
\hline Bryoria chalybeiformis & BryCha & $\mathrm{L}$ & 0 & 2 & 0 & 0 & 100 & 0 \\
\hline Bryonora pruinosa & BryPru & $\mathrm{L}$ & 0 & 0 & 3 & 0 & 0 & 100 \\
\hline Buellia elegans & BueEle & $\mathrm{L}$ & 0 & 1 & 0 & 0 & 100 & 0 \\
\hline Buellia punctata & BuePun & $\mathrm{L}$ & 12 & 20 & 8 & 32 & 48 & 20 \\
\hline Buellia terricola & BueTer & $\mathrm{L}$ & 0 & 13 & 5 & 0 & 94 & 6 \\
\hline Buellia sp.4 & BueSp4 & $\mathrm{L}$ & 0 & 5 & 5 & 0 & 47 & 53 \\
\hline Buellia sp. 5 & BueSp5 & $\mathrm{L}$ & 0 & 0 & 0 & 0 & 0 & 0 \\
\hline Caloplaca ammiospila & CalAmm & $\mathrm{L}$ & 0 & 1 & 0 & 0 & 100 & 0 \\
\hline Caloplaca jungermanniae & CalJun & $\mathrm{L}$ & 0 & 18 & 8 & 0 & 61 & 39 \\
\hline Caloplaca stillicidiorum & CalSti & $\mathrm{L}$ & 0 & 2 & 3 & 0 & 65 & 35 \\
\hline Caloplaca tirolensis & CalTir & $\mathrm{L}$ & 0 & 1 & 0 & 0 & 100 & 0 \\
\hline Caloplaca sp.5 & CalSp5 & $\mathrm{L}$ & 0 & 7 & 3 & 0 & 56 & 44 \\
\hline Caloplaca sp.6 & CalSp6 & $\mathrm{L}$ & 0 & 0 & 0 & 0 & 0 & 0 \\
\hline Candelariella aggregata & CanAgg & $\mathrm{L}$ & 12 & 4 & 5 & 39 & 16 & 45 \\
\hline Candellariella citrina & CanCit & $\mathrm{L}$ & 0 & 11 & 11 & 0 & 63 & 37 \\
\hline Cetraria muricata & CetMur & $\mathrm{L}$ & 0 & 1 & 0 & 0 & 100 & 0 \\
\hline Cladonia cariosa & ClaCar & $\mathrm{L}$ & 0 & 7 & 8 & 0 & 84 & 16 \\
\hline Cladonia cenotea & ClaCen & $\mathrm{L}$ & 0 & 0 & 3 & 0 & 0 & 100 \\
\hline Cladonia chlorophaea & ClaChl & $\mathrm{L}$ & 0 & 8 & 18 & 0 & 22 & 78 \\
\hline Cladonia fimbriata & ClaFim & $\mathrm{L}$ & 0 & 19 & 13 & 0 & 80 & 20 \\
\hline Cladonia macrophylloides & ClaMac & $\mathrm{L}$ & 0 & 16 & 5 & 0 & 86 & 14 \\
\hline Cladonia pocillum & ClaPoc & $\mathrm{L}$ & 6 & 33 & 29 & 1 & 72 & 27 \\
\hline Cladonia pyxidata & ClaPyx & $\mathrm{L}$ & 6 & 28 & 16 & 1 & 81 & 18 \\
\hline Cladonia verruculosa & ClaVer & $\mathrm{L}$ & 0 & 2 & 0 & 0 & 100 & 0 \\
\hline Cladonia sp.9 & ClaSp9 & $\mathrm{L}$ & 59 & 73 & 66 & 21 & 40 & 39 \\
\hline Cladonia sp.10 & ClaSp10 & $\mathrm{L}$ & 0 & 1 & 0 & 0 & 100 & 0 \\
\hline Collema tenax & ColTen & $\mathrm{L}$ & 0 & 7 & 5 & 0 & 74 & 26 \\
\hline Diploschistes muscorum & DipMus & $\mathrm{L}$ & 6 & 18 & 29 & 1 & 46 & 53 \\
\hline Endocarpon pusillum & EndPus & $\mathrm{L}$ & 0 & 7 & 11 & 0 & 47 & 53 \\
\hline Fuscopannaria cyanolepra & FusCya & $\mathrm{L}$ & 0 & 0 & 0 & 0 & 0 & 0 \\
\hline Lecanora laxa & LecLax & $\mathrm{L}$ & 0 & 1 & 0 & 0 & 100 & 0 \\
\hline Lecanora muralis & LecMur & $\mathrm{L}$ & 0 & 1 & 0 & 0 & 100 & 0 \\
\hline Lecanora sp.3 & LecSp3 & $\mathrm{L}$ & 0 & 0 & 3 & 0 & 0 & 100 \\
\hline Lecanora sp.4 & LecSp4 & $\mathrm{L}$ & 0 & 0 & 0 & 0 & 0 & 0 \\
\hline Lecidella wulfenii & LecWul & $\mathrm{L}$ & 0 & 1 & 0 & 0 & 100 & 0 \\
\hline Lecanora zosterae & LecZos & $\mathrm{L}$ & 0 & 0 & 0 & 0 & 0 & 0 \\
\hline Lepraria sp.1 & LepaSp1 & $\mathrm{L}$ & 0 & 0 & 0 & 0 & 0 & 0 \\
\hline
\end{tabular}


Table 2 (continued)

\begin{tabular}{|c|c|c|c|c|c|c|c|c|}
\hline \multirow[t]{2}{*}{ Taxon } & \multirow{2}{*}{$\begin{array}{l}\text { Tax. } \\
\text { Group }\end{array}$} & \multirow{2}{*}{$\begin{array}{l}\text { Code } \\
\text { (Fig. 2) }\end{array}$} & \multicolumn{3}{|c|}{ Frequency } & \multicolumn{3}{|c|}{ Mean relative abundance } \\
\hline & & & AGFI & GFI & $\mathrm{SHC}$ & AGFI & GFI & $\mathrm{SHC}$ \\
\hline Leptochidium albociliatum & LepAlb & $\mathrm{L}$ & 0 & 1 & 0 & 0 & 100 & 0 \\
\hline Leptogium intermedium & LepInt & $\mathrm{L}$ & 0 & 8 & 5 & 0 & 45 & 55 \\
\hline Leptogium lichenoides & LepLic & $\mathrm{L}$ & 0 & 13 & 8 & 0 & 58 & 42 \\
\hline Leptogium sp.4 & LeptSp3 & $\mathrm{L}$ & 0 & 0 & 3 & 0 & 0 & 100 \\
\hline Leptogium sp.5 & LeptSp4 & $\mathrm{L}$ & 6 & 18 & 24 & 3 & 27 & 70 \\
\hline Leptogium sp.6 & LeptSp5 & $\mathrm{L}$ & 0 & 5 & 0 & 0 & 100 & 0 \\
\hline Massalongia carnosa & MasCar & $\mathrm{L}$ & 0 & 1 & 0 & 0 & 100 & 0 \\
\hline Megaspora verrucosa & MegVer & $\mathrm{L}$ & 0 & 6 & 3 & 0 & 92 & 8 \\
\hline Ochrolechia upsaliensis & OchUps & $\mathrm{L}$ & 0 & 12 & 0 & 0 & 100 & 0 \\
\hline Ochrolechia turneri & OchTur & $\mathrm{L}$ & 0 & 0 & 0 & 0 & 0 & 0 \\
\hline Parmelia sulcata & ParSul & $\mathrm{L}$ & 0 & 0 & 0 & 0 & 0 & 0 \\
\hline Peltigera aphthosa & PelAph & $\mathrm{L}$ & 0 & 0 & 0 & 0 & 0 & 0 \\
\hline Peltigera canina & PelCan & $\mathrm{L}$ & 0 & 0 & 3 & 0 & 0 & 100 \\
\hline Peltigera didactyla & PelDid & $\mathrm{L}$ & 0 & 6 & 5 & 0 & 64 & 36 \\
\hline Peltigera extenuata & PelExt & $\mathrm{L}$ & 0 & 5 & 0 & 0 & 100 & 0 \\
\hline Peltigera kristinssonii & PelKri & $\mathrm{L}$ & 0 & 12 & 5 & 0 & 59 & 41 \\
\hline Peltigera malacea & PelMal & $\mathrm{L}$ & 0 & 9 & 5 & 0 & 49 & 51 \\
\hline Peltigera ponojensis & PelPon & $\mathrm{L}$ & 0 & 14 & 5 & 0 & 86 & 14 \\
\hline Peltigera rufescens & PelRuf & $\mathrm{L}$ & 12 & 27 & 16 & 11 & 54 & 35 \\
\hline Peltigera sp. 9 & PelSp9 & $\mathrm{L}$ & 0 & 15 & 11 & 0 & 48 & 52 \\
\hline Phaeorrhiza nimbosa & PhaNim & $\mathrm{L}$ & 0 & 1 & 3 & 0 & 39 & 61 \\
\hline Phaeorrhiza sareptana & PhaSar & $\mathrm{L}$ & 0 & 8 & 8 & 0 & 32 & 68 \\
\hline Physconia muscigena & PhyMus & $\mathrm{L}$ & 0 & 4 & 0 & 0 & 100 & 0 \\
\hline Placynthiella icmalea & PlaIcm & $\mathrm{L}$ & 0 & 4 & 0 & 0 & 100 & 0 \\
\hline Placynthiella uliginosa & PlaUli & $\mathrm{L}$ & 0 & 5 & 3 & 0 & 90 & 10 \\
\hline Placidium lachneum & PlaLach & $\mathrm{L}$ & 0 & 1 & 3 & 0 & 31 & 69 \\
\hline Placidium lacinulatum & PlaLaci & $\mathrm{L}$ & 0 & 13 & 0 & 0 & 100 & 0 \\
\hline Placidium squamulosum & PlaSqu & $\mathrm{L}$ & 0 & 2 & 3 & 0 & 47 & 53 \\
\hline Polychidium muscicola & PolMus & $\mathrm{L}$ & 0 & 1 & 3 & 0 & 18 & 82 \\
\hline Psora cerebriformis & PsoCer & $\mathrm{L}$ & 0 & 1 & 3 & 0 & 88 & 12 \\
\hline Psora globifera & PsoGlo & $\mathrm{L}$ & 0 & 6 & 3 & 0 & 96 & 4 \\
\hline Psora montana & PsoMon & $\mathrm{L}$ & 0 & 1 & 0 & 0 & 100 & 0 \\
\hline Psora sp.4 & PsoSp4 & $\mathrm{L}$ & 0 & 7 & 3 & 0 & 81 & 19 \\
\hline Rinodina conradii & RinCon & $\mathrm{L}$ & 0 & 2 & 3 & 0 & 57 & 43 \\
\hline Rinodina olivaceobrunnea & RinOli & $\mathrm{L}$ & 0 & 1 & 0 & 0 & 100 & 0 \\
\hline Rinodina terrestris & TrinTer & $\mathrm{L}$ & 0 & 2 & 3 & 0 & 61 & 39 \\
\hline Squamarina lentigera & SquLen & $\mathrm{L}$ & 0 & 0 & 0 & 0 & 0 & 0 \\
\hline Thelenella muscorum & TheMus & $\mathrm{L}$ & 0 & 0 & 0 & 0 & 0 & 0 \\
\hline Xanthoparmelia wyomingica & XanWyo & $\mathrm{L}$ & 0 & 0 & 0 & 0 & 0 & 0 \\
\hline Anthoceros sp1. & AntSp1 & $\mathrm{B}$ & 6 & 2 & 5 & 50 & 13 & 37 \\
\hline Aulacomnium androgynum & AulAnd & $\mathrm{B}$ & 0 & 0 & 0 & 0 & 0 & 0 \\
\hline Brachythecium fendleri & BraFen & $\mathrm{B}$ & 0 & 1 & 0 & 0 & 100 & 0 \\
\hline Bryum argenteum & BryArg & $\mathrm{B}$ & 29 & 51 & 37 & 13 & 52 & 35 \\
\hline
\end{tabular}


Table 2 (continued)

\begin{tabular}{|c|c|c|c|c|c|c|c|c|}
\hline \multirow[t]{2}{*}{ Taxon } & \multirow{2}{*}{$\begin{array}{l}\text { Tax. } \\
\text { Group }\end{array}$} & \multirow{2}{*}{$\begin{array}{l}\text { Code } \\
\text { (Fig. 2) }\end{array}$} & \multicolumn{3}{|c|}{ Frequency } & \multicolumn{3}{|c|}{ Mean relative abundance } \\
\hline & & & AGFI & GFI & $\mathrm{SHC}$ & AGFI & GFI & $\mathrm{SHC}$ \\
\hline Bryum sp.2 & BrySp2 & $\mathrm{B}$ & 0 & 5 & 3 & 0 & 72 & 28 \\
\hline Cephaloziella divaricata & CepDiv & $\mathrm{B}$ & 18 & 24 & 24 & 17 & 44 & 38 \\
\hline Ceratodon purpureus & CerPur & $\mathrm{B}$ & 6 & 15 & 8 & 6 & 87 & 8 \\
\hline Dicranum montanum & DicMon & $\mathrm{B}$ & 0 & 2 & 0 & 0 & 100 & 0 \\
\hline Dicranum scoparium & DicSco & $\mathrm{B}$ & 0 & 1 & 0 & 0 & 100 & 0 \\
\hline Didymodon vinealis & DidVin & $\mathrm{B}$ & 0 & 6 & 0 & 0 & 100 & 0 \\
\hline Encalypta vulgaris & EncVul & $\mathrm{B}$ & 24 & 42 & 32 & 17 & 44 & 38 \\
\hline Eurhynchiastrum pulchellum & EurPul & $\mathrm{B}$ & 0 & 13 & 5 & 0 & 42 & 58 \\
\hline Fossombronia spp. & FosSp1 & $\mathrm{B}$ & 0 & 2 & 0 & 0 & 100 & 0 \\
\hline Funaria hygrometrica & FunHyg & $\mathrm{B}$ & 0 & 0 & 0 & 0 & 0 & 0 \\
\hline Gemmabryum caespiticium & GemCae & $\mathrm{B}$ & 6 & 46 & 26 & 3 & 72 & 25 \\
\hline Homalothecium aureum & HomAur & $\mathrm{B}$ & 6 & 22 & 26 & 1 & 44 & 55 \\
\hline Plagiomnium spp. & PlagSp1 & $\mathrm{B}$ & 0 & 0 & 0 & 0 & 0 & 0 \\
\hline Polytrichum juniperinum & PolJun & $\mathrm{B}$ & 0 & 20 & 3 & 0 & 99 & 1 \\
\hline Polytrichum piliferum & PolPil & $\mathrm{B}$ & 0 & 9 & 3 & 0 & 98 & 2 \\
\hline Pterygoneurum ovatum & PteOve & $\mathrm{B}$ & 0 & 4 & 3 & 0 & 47 & 53 \\
\hline Pterygoneurum subsessile & PteSub & $\mathrm{B}$ & 0 & 6 & 0 & 0 & 100 & 0 \\
\hline Riccia sorocarpa & RicSor & $\mathrm{B}$ & 0 & 1 & 3 & 0 & 26 & 74 \\
\hline Syntrichia caninervis & SynCan & $\mathrm{B}$ & 24 & 8 & 8 & 19 & 19 & 62 \\
\hline Syntrichia montana & SynMon & $\mathrm{B}$ & 0 & 1 & 3 & 0 & 3 & 97 \\
\hline Syntrichia ruralis & SynRur & $\mathrm{B}$ & 65 & 93 & 92 & 6 & 31 & 64 \\
\hline
\end{tabular}

$A G F I$, agricultural grass-forb interspace; $G F I$, (native) grass-forb interspace; $S H C$, shrub canopy

primary drivers of bryophyte cover, whereas northness and minimum insolation were the strongest predictors of lichen cover (Fig. 5a, b). Models of cover were similar in key ways among

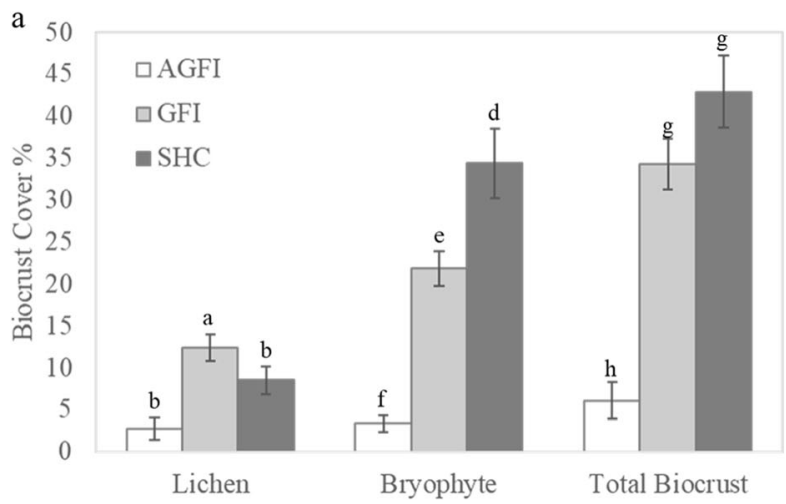

Fig. 2 Biocrust cover (a) and species richness (b) by microhabitat type were different for both functional groups and overall $(p<0.01)$. Error bars represent one standard error of the mean. Letters above bars indicate post-hoc differences within a group bryophytes and lichens, but also displayed a few distinctions. They were similar in that minimum insolation and northness were among the major drivers, and the general response to those gradients

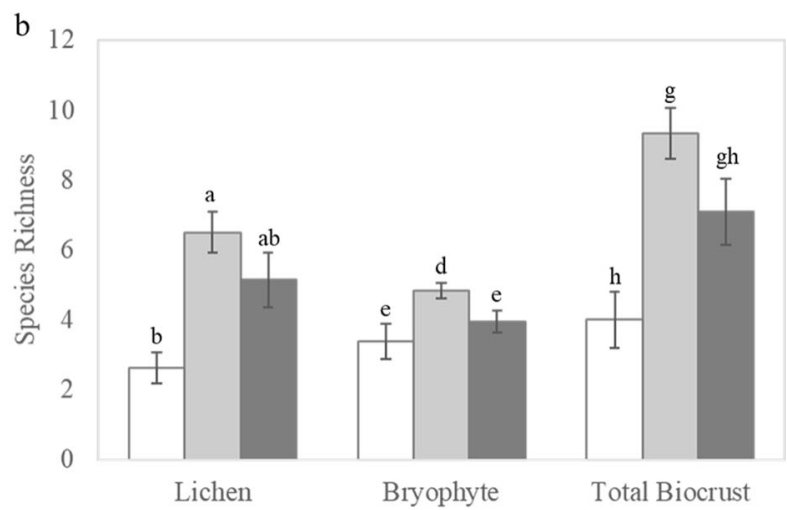

(lichen, bryophyte or total) using Tukey's HSD. Microsites include agricultural grass and forb interspace (AGFI), native grass and forb interspace (GFI) and shrub canopy (SHC) 


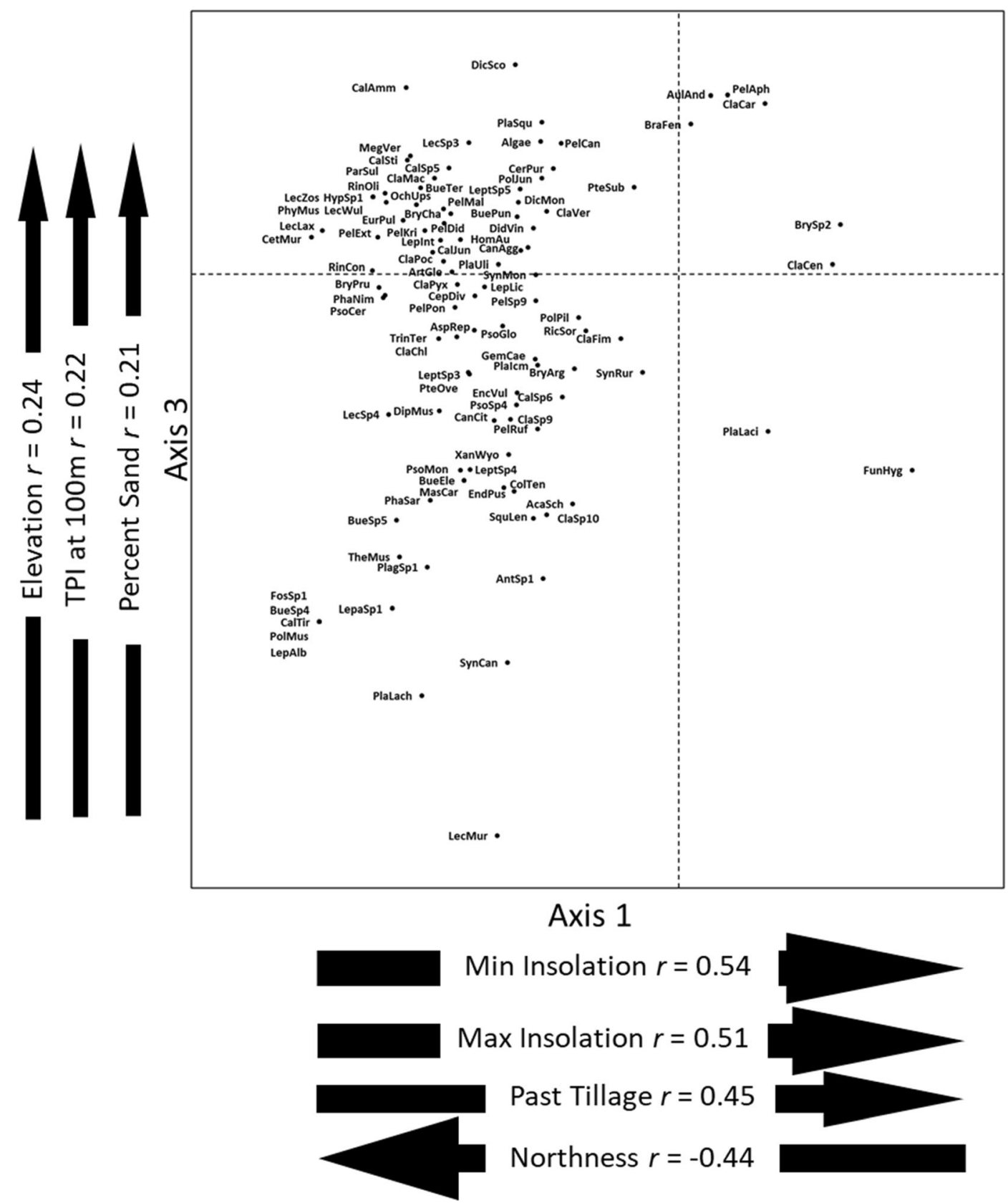

Fig. 3 Centroids of species in NMDS ordination space. Dashed lines indicate the 0 position an axis 1 and 3. Codes identifying taxa are defined in Table 2

was similar (positive responses to northness, negative responses to minimum insolation). We found that the marginal effect of winter minimum insolation on bryophyte cover was generally negative and non-linear, where increasing solar inputs from $3 \mathrm{MJ} \mathrm{m}^{-2}$ to $6 \mathrm{MJ} \mathrm{m}^{-2}$ starkly diminished cover, though additional inputs did not reduce cover (Fig.
$5 b)$. We observed a more gradual pattern in lichen cover with strong negative effects at $4 \mathrm{MJ} \mathrm{m}^{-2}$, with increasing solar inputs leading to a more gradual decrease in cover. In both functional groups, past tillage had a negative effect, though this effect was stronger among the bryophytes. Bryophytes were distinct from lichens in that their 


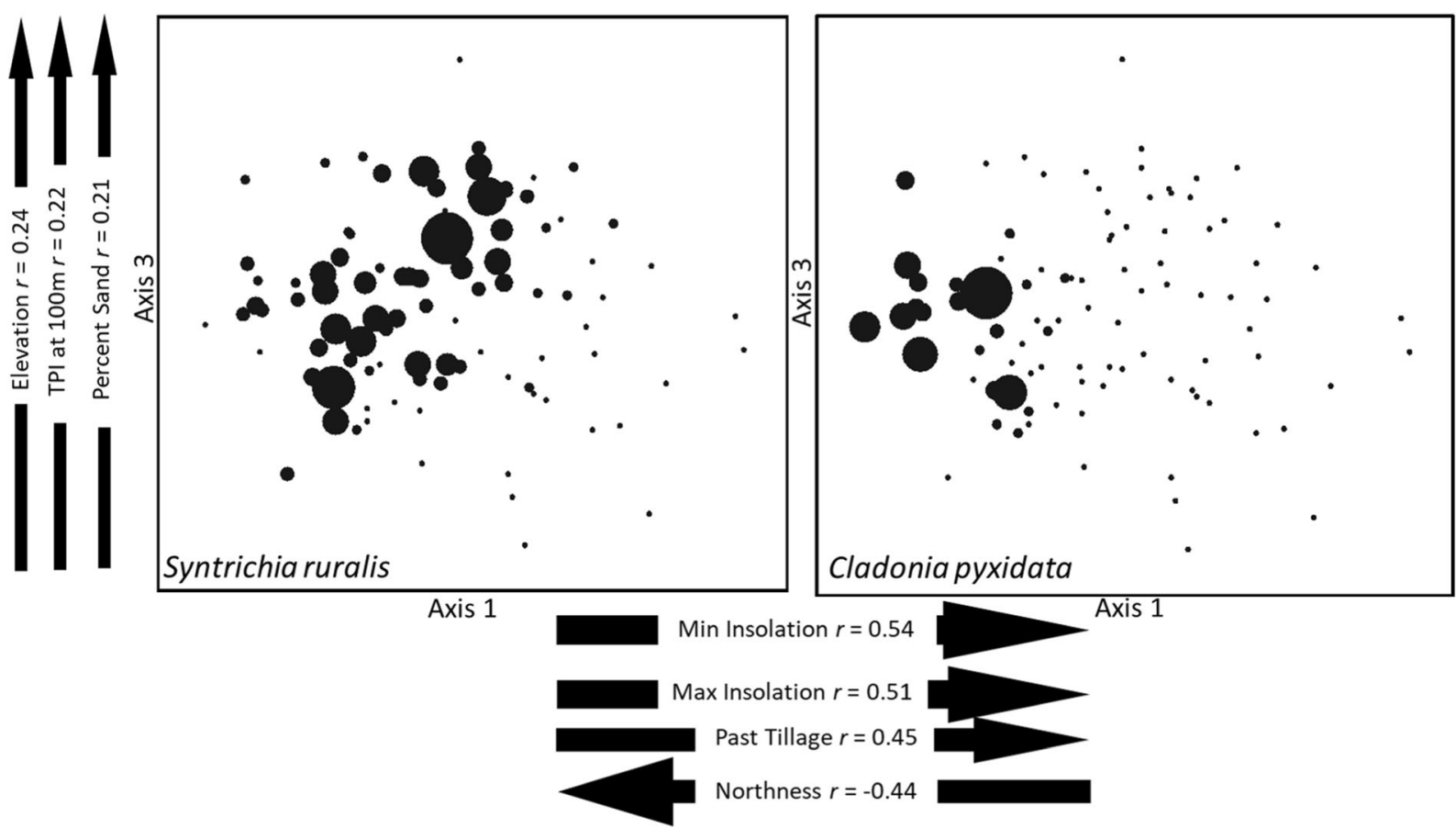

Fig. 4 Plots in NMDS ordination space, scaled to the abundance of 2 prevalent species, a moss (Syntrichia ruralis) and a lichen (Cladonia pyxidata). Larger symbols indicate a greater abundance of the indicated species. Axes 1 \& 3 of a 3 -axis ordination are shown

cover was also strongly determined by past tillage and percent sand, and to a lesser extent by TPI at $100 \mathrm{~m}$. Bryophyte cover was abruptly elevated when sand content exceeded about $70 \%$, and was reduced by about a third when the location had been tilled. Bryophyte cover increased when $100 \mathrm{~m}$ radius TPI exceeded $\sim 6$, suggesting that bryophytes were more abundant on meso-scale prominences and areas closer to ridgelines. Lichens were also positively influenced, though more weakly, by higher levels of low and meso-scale TPI. Our models of lichen and bryophyte cover are mapped in Fig. 5c, d.

Table 3 Performance metrics from random forest models for cover and richness of lichen and bryophyte functional groups. We report pseudo- $\mathrm{R}^{2}$ and mean squared error values calculated from out-of-bag samples

\begin{tabular}{lll}
\hline Response & Pseudo- $\mathrm{R}^{2}$ & Mean squared error \\
\hline Lichen Cover & 0.33 & 123.62 \\
Bryophyte Cover & 0.33 & 228.88 \\
Lichen Richness & 0.24 & 33.77 \\
Bryophyte Richness & 0.09 & 5.25 \\
\hline
\end{tabular}

Biocrust richness along environmental gradients

We were less successful in modeling richness patterns of bryophytes (Table 3, pseudo $R^{2}=0.09$, Mean Squared Error $=5.2$ ) compared to lichens (Table 3, pseudo $R^{2}=0.24$, Mean Squared Error $=33.8$ ). Nonetheless, our model indicates the richness of the two groups was driven, like cover, primarily by insolation and northness (Fig. 6a). Sites with low solar inputs had the greatest species richness in both functional groups, and both models showed stepped responses when increasing solar inputs, perhaps due to physiological thresholds of certain species or groups of species (Fig. 6b). Eastness and past tillage were also important predictors of the richness of both groups. We observed that mosses had greater species diversity on eastern aspects, and lichens had greater diversity on western aspects. Tillage had a negative impact on richness of both functional groups. Finally, elevation strongly influenced bryophyte richness, such that low elevations exhibited low richness and the highest values were observed at intermediate elevations (Fig. 6b). Lichen richness was not strongly influenced by elevation (Fig. 6b). Our models of lichen and bryophyte richness are shown in Fig. 6c, d. 

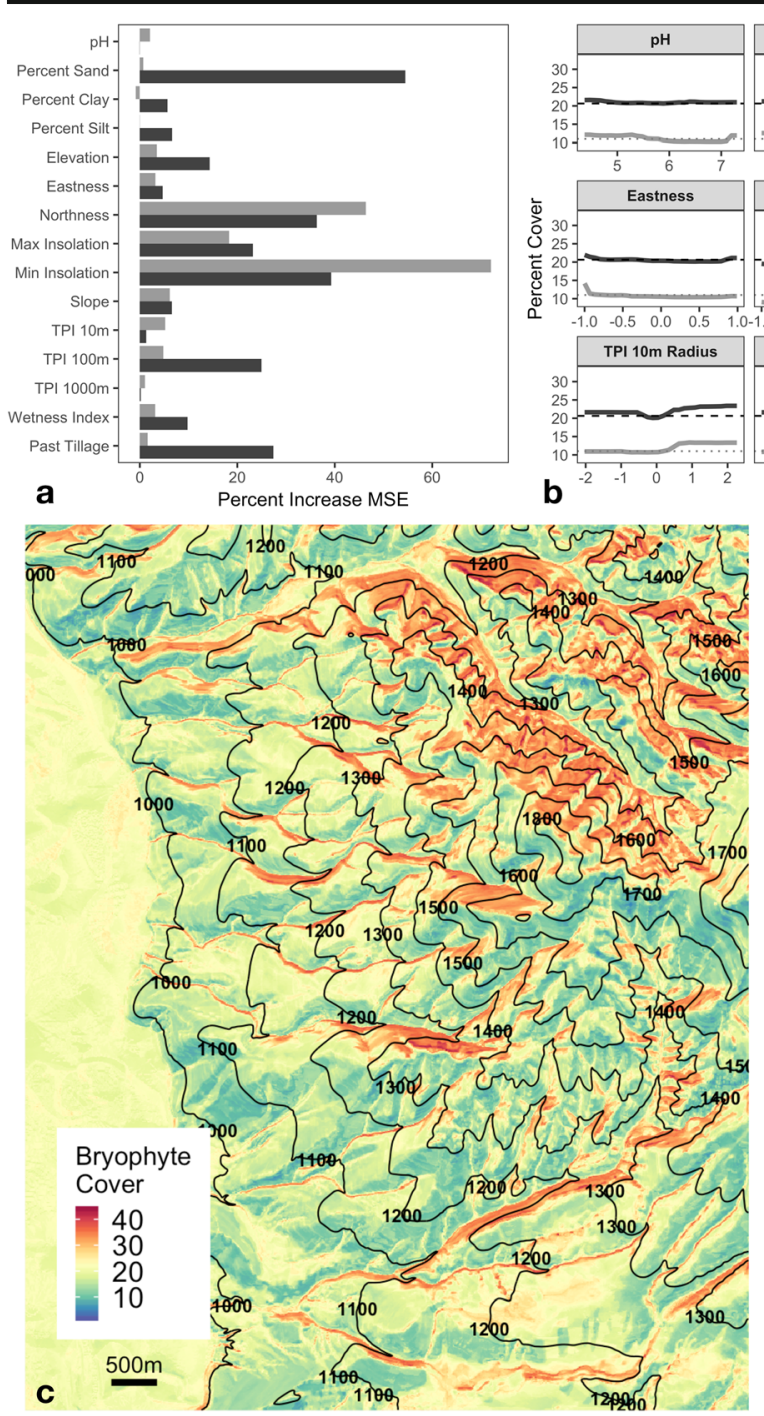

Fig. 5 a The variable importance measures for lichen (grey bars) and bryophyte (black bars) cover models, where importance is defined as the percent increase in mean squared error when a variable of interest is left out of the model. b Partial dependence plots depicting the marginal effect of a predictor, $\mathrm{x}$-axis, on the
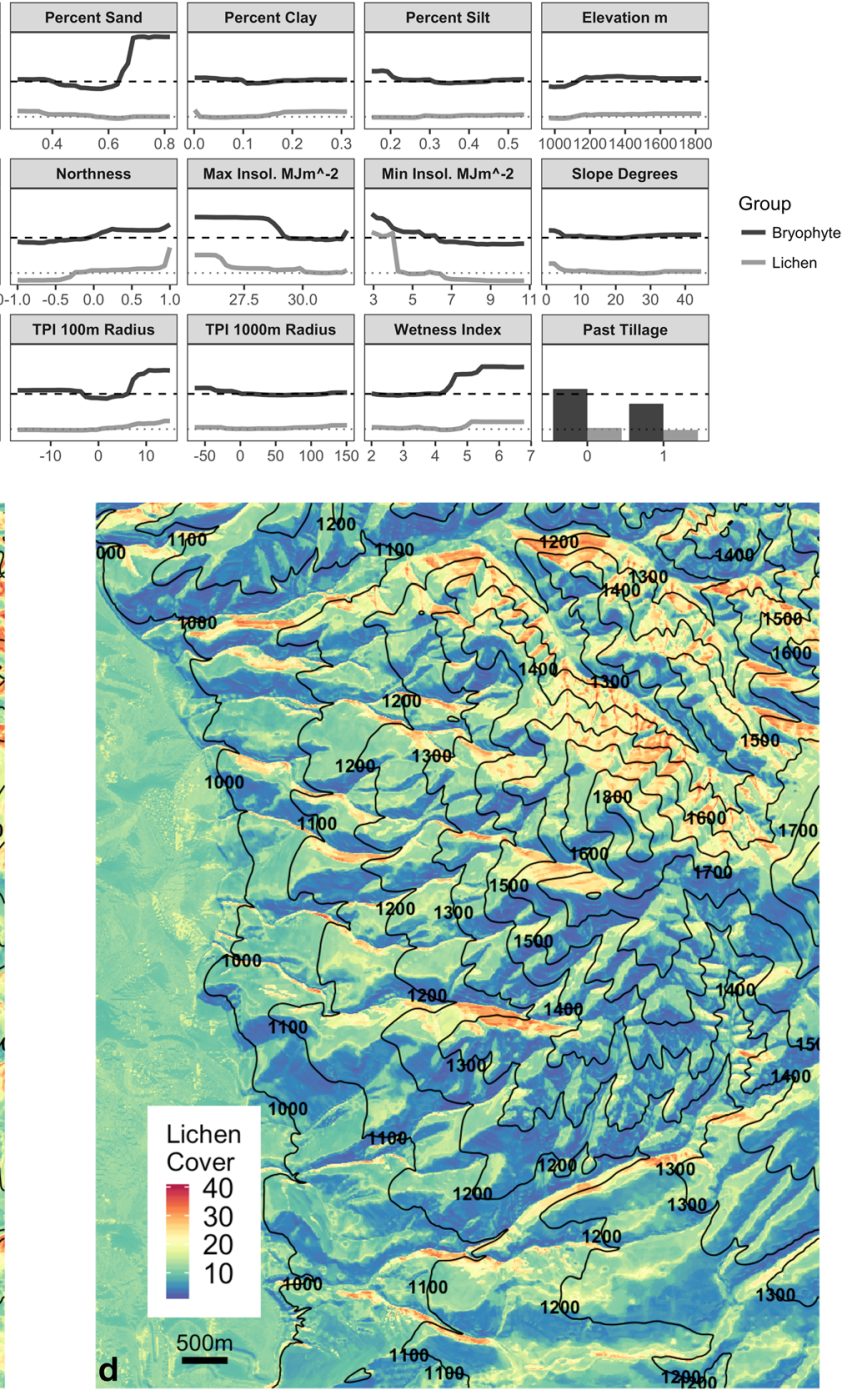

cover response, y-axis, for lichens (solid gray lines) and bryophytes (solid black lines). Survey wide means for lichen and bryophyte cover are depicted as dotted and dashed lines. Predictive surfaces for bryophyte $\mathbf{c}$ and lichen $\mathbf{d}$ cover

\section{Discussion}

Drivers of biocrust community diversity and abundance

Several studies have documented the biocrusts of the intermountain west (eg. Ponzetti and McCune 2001, Ponzetti et al. 2007; DeBolt 2008; Root and McCune 2012). As in these studies, we found diverse and abundant biocrust communities shaped by a variety of environmental factors, including vegetation type,

insolation, aspect, tillage history and soil texture. Overall, we observed that biocrust communities separated based on insolation, soil texture, disturbance history and aspect. While individual species varied in some regards, we saw that the general patterns were similar, suggesting environmental constraints on where biocrust can thrive. The fact that the model was only able to explain a portion of the cover and richness may indicate stronger biological influences on community composition. 


\section{Insolation and correlates across the landscape}

The most important predictor of species richness and cover was insolation, with most species preferring areas with lower insolation and/or northness. This may be related to poikilohydry in biocrust species, because the ultimate control of biocrust growth across all species is hydration time (Bowker et al. 2016). Lower insolation values are likely positively correlated with soil moisture, which governs water balance and hydration period length following precipitation events. Further, higher insolation is indicative of heat load, whereby south facing sites receive more afternoon sun, generating thermal conditions beyond the physiological tolerances of the majority of biocrust species. Because high and low insolation sites are often adjacent, we might hypothesize that all or most of our species pool can disperse to both high and low insolation environments, but most are filtered from the community under the high insolation condition.

Only a small minority of species showed affinity for high insolation, but in these areas, whether disturbed or not, we observed less biocrust cover. The species we see occurring in high insolation space are ruderal, disturbance colonizing species (eg. Bryum sp.) or species that are widely dispersed in more arid regions (eg. Placidium sp.). Moderate insolation values did result in an increase in lichen richness on west facing slopes, suggesting that high insolation may be a strong environmental filter, but that low insolation is not required by all community members.

\section{Disturbance across the landscape}

Disturbance history was another important driver, correlated here with lower elevation agricultural grasslands, because this vegetation type was treated with recent tillage (within 10 years of sampling time), possibly repeatedly and long-term, and has a history of heavy use by sheep and cattle. Some of these areas have been further altered by restoration activities aimed at promoting native vascular plant species over exotics. Restoration treatments include herbicide applications and drill seeding. Although tillage might not be a universal disturbance for biocrusts, compressional forces that disrupt the soil surface, such as ORV tracks, livestock hooves, or chaining similarly reduce biocrust cover and diversity (Zaady et al. 2016). Bryophytes were more common than lichens in these tilled areas, possibly because they can establish more quickly than lichens and may be more tolerant to repeated disturbance because of a soil propagule bank (Smith 2013). Given frequent tillage, the number of species and cover (average $=6 \%$ cover, 3 species) suggest that either biocrust may colonize after disturbance, or remnant biocrusts may persist that escaped disturbance.

Insolation and disturbance history tended to be correlated drivers, in that high insolation areas were more likely to have been tilled and subsequently invaded by exotic plants. Soils in high insolation areas tended to be physically unstable for this and other reasons, and the biocrust present was usually found in very close proximity to vascular plants. These areas consisted of bare soil and annual weeds, often cheatgrass (Durham et al. 2017). Nevertheless, we can assert that the inclusion of past tillage in our models did contribute additional predictive power, beyond that attributable to insolation, especially in models of bryophyte cover and lichen richness.

\section{Edaphic drivers across the landscape}

Soil texture, but not $\mathrm{pH}$, was a strong influence on bryophyte cover, and a modest influence on biocrust community structure, but was relatively inconsequential for lichen cover or richness. Overall, edaphic effects were substantially weaker than topographic effects related to insolation. This finding contrasts with several other studies in the region (Ponzetti and McCune 2001, 2007; Root and McCune 2012), which found stronger influences of texture and $\mathrm{pH}$. We believe that although the edaphic environment is certainly important to biocrusts in general, its importance relative to other factors is based on its local variation in a given study area; thus this result will vary from study to study. Our soil $\mathrm{pH}$ and texture data had a low variance compared to the other studies and to our insolation data. In contrast, studies conducted in areas with a greater diversity of soil parent materials or weathering environments are likely to display strong edaphic control on biocrust abundance and structure (Bowker et al. 2006).

\section{Small-scale patterns}

Interspaces of agricultural grasslands showed the lowest cover and richness of any vegetation type. These results mimic the influence of disturbance at the larger scale, since these microsites are also the most disturbed within sites. Lower richness and 


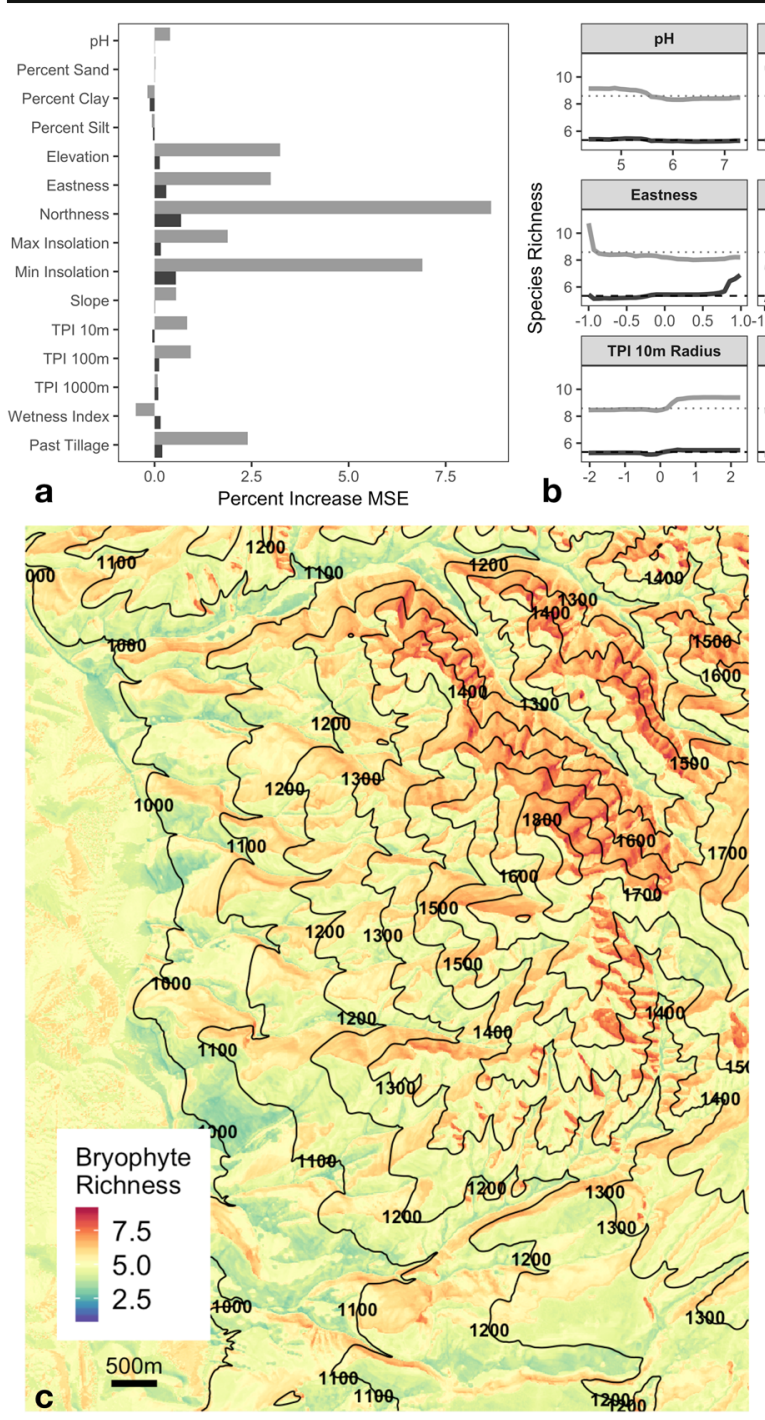

Fig. 6 a The variable importance measures for lichen (grey bars) and bryophyte (black bars) richness models, where importance is defined as the percent increase in mean squared error when a variable of interest is left out of the model. b Partial dependence plots depicting the marginal effect of a predictor, $\mathrm{x}$-axis, on the

cover of biocrusts were often found under shrub canopies compared to native grass-forb interspaces. These results contrast with the results at the larger scale, because the habitats under shrub canopies are low insolation and therefore would be expected to have higher levels of cover and diversity. Other studies of low-insolation microsites in other regions support this expectation (Bowker et al. 2006; Li et al. 2010; Nejidat et al. 2016). Reduction of available biocrust habitat due to litter accumulation under shrubs is one likely explanation
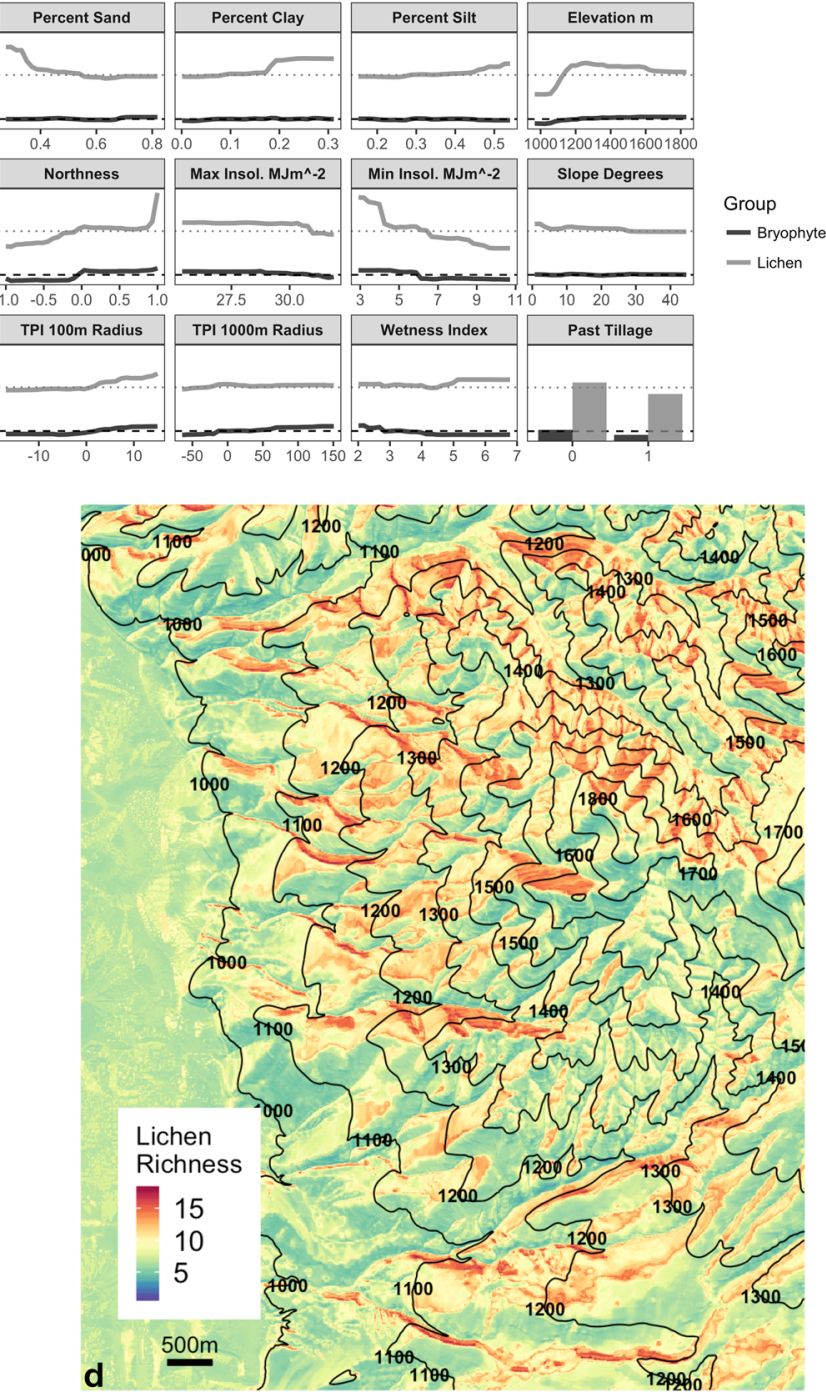

species richness response, y-axis, for lichens (solid gray lines) and bryophytes (solid black lines). Survey wide means for lichen and bryophyte richness are depicted as dotted and dashed lines. Predictive surfaces for bryophyte $\mathbf{c}$ and lichen $\mathbf{d}$ richness

of why our results differed. The type of vascular plant overstory also led to species turnover. For example, beneath shrubs diversity was low, with bryophytes dominating, usually Syntrichia ruralis. The grass-forb interspace generally had more lichens and greater diversity, and the cover was usually dominated by Cladonia spp. and Syntrichia ruralis, with other lichen and bryophyte species interspersed. These findings suggest that the vegetation community is important in shaping the biocrust community composition. 
Regional comparison of biocrust species composition

Our survey documents a diverse biocrust community. Across the entire study area, the 96 taxa we detected accounts for $14 \%$ of the known primary producer $\gamma$ diversity. The species richness at the individual plot scale $($ mean $=14)$ compares favorably to the average vascular plant richness (mean $=19$, unpublished data).

A portion of our community members are widespread across western North America and also occur in more arid regions of the southwestern United States. For example, Syntrichia ruralis is cosmopolitan, with genotypic variation related to its home climate (Massatti et al. 2017). Similarly, a suite of lichen and bryophyte species are also found in more arid regions such as the Colorado Plateau, Sonoran, Mojave and Chihuahuan Deserts (example lichen genera: Psora, Placidium, and moss genera: Bryum and Gemmabryum).

Biocrust communities in our study area share the greatest affinity with Columbia Basin and Great Plains communities (Ponzetti and McCune 2001; Ponzetti et al. 2007; McCune and Rosentreter 2007; Lesica 2012, 2017), and substantial overlap with Great Basin communities (St. Clair et al. 1993; Freund 2015). Our community overlaps in common lichen species of Cladonia, Psora, and Placidium, as well as abundant Diploschistes muscorum. Numerous species of Peltigera also made up a large part of our biocrust, similar to the Columbia Basin community (Ponzetti and McCune 2001), though these aren't common in the warmer arid ecoregions. Liverwort Cephaloziella divaricata is a common member of our crust community, sometimes creating an overall black biocrust. This liverwort was detected in other Columbia Basin studies, but to our knowledge, there are no published accounts of this species in the Great Basin Desert (Ponzetti and McCune 2001; Ponzetti et al. 2007). Ponzetti et al. (2007) frequently encountered Leptochidium albociliatum and Acarospora schleicheri in their Columbia Basin study, though these species were rarely encountered in our study area. Collema spp., more common in the Great Basin and other regions, was not common in our study. Instead, cyanolichen Leptogium spp. often occurred with Cephaloziella divaricata's black crust. Some lichen species were commonly seen only as a few apothecia with low cover, such as Lecanora spp. and Rinodina spp. Other minute crustose lichen species reached greater cover and were sometimes locally abundant, such as Buellia spp. and
Caloplaca jungermanniae. Some of the species rarely encountered or seen just once include Leptochidium albociliatum, Acarospora schleicheri, Massalongia carnosa, and Thelenella muscorum. In other areas of the Columbia Basin or Great Basin, the species above can occur in greater abundance.

A final floristic element worth noting is Bryoria chalybeiformis. This species grew in very steep areas of low insolation, which is of interest because this largestatured fruticose species is more common in alpine or tundra habitats (McCune et al. 2014). It was often locally abundant in cool aspects, but sometimes only growing as a few strands among other species. This species does not appear to be common in biocrusts of the neighboring ecoregions of the Columbia Basin or Great Basin, and may be a more unique component of biocrusts in our intermountain area. As there are few published studies on the Montanan biocrust, we cannot determine if alpine-tundra disjuncts are typical, but this suggests an intriguing area for future investigation.

Biocrust conservation and restoration tools and implications

Biocrusts have conservation and restoration value for two primary reasons: 1 . They may contribute considerably to local biodiversity, 2. They perform valuable ecosystem functions. Our predictive maps are useful in understanding the distributions of biocrust diversity in this ecoregion, but have some important limitations. Our maps apply only to non-forested areas because forests were excluded from sampling. The potential for errant interpretation is most apparent in model predictions at high elevations with northern aspects, areas that are densely treed. In these areas our models predicted high levels of biocrust cover and species richness, though, in reality, lower light availability and organic matter accumulation preclude the occurrence of biocrusts. Thus, dominant vegetation type should be considered in conjunction with these predictive maps when developing management plans for biocrust. Additionally, since models explain only $9-24 \%$ of the variance in richness, high diversity predicted by the maps should be verified on-site. The proper usage of the maps is to identify locations that are more likely to be species rich, not to make a precise estimate of richness. We suggest that these maps, in conjunction with information about the diversity of other taxa, can assist MPG Ranch managers in the location of local biodiversity hotspots wherein 
maintenance of biodiversity would be the primary management goal. Since common restoration activities (e.g. drill seeding) may disturb the soil surface, these maps could be useful in directing such activities to areas where there are unlikely to induce biocrust biodiversity loss.

Biocrusts have gained attention for their ecosystem value in stabilizing soils, promoting soil fertility, and enhancing water holding capacity and retention (Maestre et al. 2016). Additionally biocrusts may have positive or negative interactions with vascular plants (Reisner et al. 2013; Kidron 2014; Zhang et al. 2016; Xiao and Hu 2017; Xiao and Veste 2017). Of particular regional importance, biocrusts may reduce the germination or establishment of annual weeds such as Bromus tectorum (Zaady et al. 2003; Condon and Pyke 2016). However, they may also enhance Bromus tectorum growth by increasing soil fertility (Ferrenberg et al. $2017 \mathrm{a}, \mathrm{b}$ ). In areas where the potential benefits outweigh the potential risks, biocrust rehabilitation may become a valuable ecological restoration approach; nevertheless, restoration practitioners often do not consider biocrusts in restoration efforts at all.

The first step in the use of biocrusts for restoration is to determine the distribution and preferred habitat of biocrust communities. The finding that the majority of species performed better in low insolation sites suggests that restoration activities may be more successful if sited in such areas to create propagule source sites, or if insolation is buffered through artificial means (e.g. placement of jute cloth on the soil surface; Condon and Pyke 2016). Since many biocrust organisms can be artificially grown (Condon and Pyke 2016; Bowker et al. 2017), our results are useful in determining appropriate species to culture for restoration applications in various settings. One logical approach is to target the most widespread species such as Syntrichia ruralis and Bryum spp. These have been explored as restoration species elsewhere (Doherty et al. 2015; Bu et al. 2017), and we have noted that these species are early to colonize naturally in disturbed areas in our study. Another approach to enhance success in difficult high insolation locations is to target the species that appear to be most tolerant of these habitats, including Funaria hygrometrica and Bryum spp. With biocrust additions to field sites, from either field collections or greenhouse or field cultivation, colonization of these and other taxa can likely be enhanced to assist more rapid recovery, and enhanced ecosystem function (Belnap 1993; Zhao et al. 2016; Antoninka et al. 2017).
Acknowledgements We thank the MPG Ranch for support. We thank Mary Ellyn DuPre for her hard work on data collection and bryophyte identification. We thank Peter Chuckran for lab and field assistance. We thank Bruce McCune and members of Northwest Lichenologists for their help with lichen identification.

Open Access This article is distributed under the terms of the Creative Commons Attribution 4.0 International License (http:// creativecommons.org/licenses/by/4.0/), which permits unrestricted use, distribution, and reproduction in any medium, provided you give appropriate credit to the original author(s) and the source, provide a link to the Creative Commons license, and indicate if changes were made.

\section{References}

Antoninka A, Bowker M, Chuckran P, Barger NN, Reed SC, Belnap J (2017) Maximizing establishment and survivorship of field-collected and greenhouse-cultivated biocrusts in a semi-cold desert. Plant Soil. https://doi.org/10.1007/s11104017-3300-3

Belnap J (1993) Recovery rates of cryptobiotic crusts: inoculant use and assessment methods. Great Basin Nat 53:89-95

Belnap J, Lange OL (eds) (2003) Biological soil crusts: structure function and management. Springer-Verlag, Berlin

Biondini ME, Bonham CD, Redente EF (1985) Secondary successional patterns in a sagebrush (Artemisia tridentata) community as they relate to soil disturbance and soil biological activity. Vegetatio 60:25-36

Boehner J, Koethe R, Conrad O, Gross J, Ringeler A, Selige T (2002) Soil Regionalisation by means of terrain analysis and process parameterisation. In: Soil classification 2001. European Soil Bureau, Research Report No. 7. Ed. E. Micheli, F Nachtergaele, L Montanarella. pp. 213-222. Office for Official Publications of the European Communities, Luxembourg

Bowker MA, Belnap J, Davidson DW, Goldstein H (2006) Correlates of biological soil crust abundance across a continuum of spatial scales: support for a hierarchical conceptual model. J Appl Ecol 43:152-163

Bowker MA, Mau RL, Maestre FT, Escolar C, Castillo-Monroy AP (2011) Functional profiles reveal unique ecological roles of various biological soil crust organisms. Functional Ecology 25(4):787-795

Bowker MA, Belnap J, Büdel B, Sannier C, Pietrasiak N, Eldridge DJ, Rivera-Aguilar V (2016) Controls on distribution patterns of biological soil crusts at micro- to global scale. In Biological soil crusts: an organizing principle in drylands. Eds. B Weber, B Büdel, J Belnap. pp. 173-198. Springer, Berlin

Bowker MA, Antoninka AJ, Durham RA (2017) Applying community ecological theory to maximize productivity of cultivated biocrusts. Ecol Appl 27(6):1958-1969

Breiman L (2001) Random forests. Mach Learn 45:5-32

Bu C, Li R, Wang C, Bowker MA (2017) Successful field cultivation of moss biocrusts on disturbed soil surfaces. Plant Soil https://doi.org/10.1007/s11104-017-3453-0 
Condon LA, Pyke DA (2016) Filling the interspace-restoring arid land mosses: source populations, organic matter, and overwintering govern success. Ecol. Evol. 6:7623-7632

Corripio JG (2014) Insol: solar radiation. R package version 1.1.1, 2014

Cutler DR, Edwards TC, Beard KH, Cutler A, Hess KT, Gibson J, Lawler JJ (2007) Random forests for classification in ecology. Ecology 88:2783-2792

DeBolt A (2008) Biological soil crust survey of the Birch Creek area, Malheur County, Oregon. Prepared for the Bureau of Land Management, Oregon State Office, Portland, OR. (available at: https://www.fs.fed.us/r6 /sfpnw/issssp/documents/inventories/inv-rpt-br-and-li-valbirchck-bio-soil-crust-surveys-2008-12.pdf)

Delgado-Baquerizo M, Morillas L, Maestre FT, Gallardo A (2013) Biocrusts control the nitrogen dynamics and microbial functional diversity of semi-arid soils in response to nutrient additions. Plant and Soil 372(1-2):643-654

Doherty KD, Antoninka AJ, Bowker MA, Ayuso SV, Johnson NC (2015) A novel approach to cultivate biocrusts for restoration and experimentation. Ecol Rest 33:13-16

Doherty KD, Butterfield BJ, Wood TE (2017) Matching seed to site by climate similarity: techniques to prioritize plant materials development and use in restoration. Ecol Appl 27:10101023

Dufrene M, Legendre P (1997) Species assemblages and indicator species: the need for a flexible asymmetrical approach. Ecol Monogr 67:345-366

Durham RA, Mummey DL, Shreading L, Ramsey PW (2017) Phenological Patterns Differ between Exotic and Native Plants: Field Observations from the Sapphire Mountains, Montana. Natural Areas Journal 37(3):361-381

Ferrenberg S, Faist AM, Howell A, Reed SC (2017a) Biocrusts enhance soil fertility and Bromus tectorum growth and interact with warming to influence germination. Plant Soil. https://doi.org/10.1007/s11104-017-3525-1

Ferrenberg S, Tucker CL, Reed SC (2017b) Biological soil crusts: diminutive communities of potential global importance. Front Ecol Environ 15:160-167

Freund SM (2015) Biological soil crust cover and richness in two Great Basin vegetation zones. Available from ProQuest Dissertations \& Theses Global (1760591311). Retrieved from https://search-proquest-com.weblib.lib.umt.edu:2443 /docview/1760591311 ?accountid=14593

Friedman J, Hastie T, Tibshirani R (2001) The elements of statistical learning (Vol. 1). Springer series in statistics. Springer, Berlin

Gee GW, Bauder JW (1986) Particle-size analysis. In Methods of Soil Analysis, Part 1. Physical and Mineralogical Methods. Agronomy Monograph No. 9 (2ed). Ed. A Klute. p. 383-411. American Society of Agronomy/Soil Science Society of America, Madison, Wisconsin

Genuer R, Poggi JM, Tuleau-Malot C (2010) Variable selection using random forests. Pattern Recogn Lett 31:2225-2236

Gesch D, Oimoen M, Greenlee S, Nelson C, Steuck M, Tyler D (2002) The national elevation dataset. Photogramm Eng Rem S 68:5-32

Hijmans RJ, Cameron SE, Parra JL, Jones PG, Jarvis A (2005) Very high resolution interpolated climate surfaces for global land areas. Int J Climatol 25:1965-1978
Hutchinson GE (1957) Concluding remarks. Cold Spring Harb Symp Quant Biol 22:415-427

Kidron GJ (2014) The negative effect of biocrusts upon annualplant growth on sand dunes during extreme droughts. J Hydrol 508:128-136

Kraft NJ, Adler PB, Godoy O, James EC, Fuller S, Levine JM (2015) Community assembly, coexistence and the environmental filtering metaphor. Funct Ecol 29:592-599

Kruskal JB (1964) Nonmetric multidimensional scaling: A numerical method. Psychometrika 29(2):115-129

Lesica P (2012) Manual of Montana Vascular Plants BRIT Press, Fort Worth, TX

Lesica P (2017) 2017 Friends of the University of Montana Herbarium Newsletter Newsletters of the Friends of the University of Montana Herbarium 22 (available at: https://scholarworks.umt.edu/cgi/viewcontent. cgi? article $=1021 \&$ context=herbarium newsletters)

Li X-R, He M-Z, Zerbe S, Li X-J, Liu L-C (2010) Microgeomorphology determines community structure of biological soil crusts are small scales. Earth Surf Process Landf 35: 932-940

Maestre FT, Eldridge DJ, Soliveres S, Kéfi S, Delgado-Baquerizo M, Bowker M, Berdugo M (2016) Structure and functioning of dryland ecosystems in a changing world. Ann Rev Ecol Evol S 47:215-237

Massatti R, Doherty KD, Wood TE (2017) Resolving neutral and deterministic contributions to genomic structure in Syntrichia ruralis (Bryophyta, Pottiaceae) informs propagule sourcing for dryland restoration. Conserv Genet. https://doi. org/10.1007/s10592-017-1026-7

McCune B, Grace JB (2002) Analysis of ecological communities. MjM Software, pp. 304. Gleneden Beach, Oregon, USA

McCune B, Rosentreter R (2007) Biotic soil crust lichens of the Columbia Basin, Monographs in North American Lichenology Vol. 1. Northwest Lichenologists, Corvallis, Oregon

McCune B, Rosentreter R, Spribille T, Breuss O, Wheeler T (2014) Montana lichens: an annotated list. Monographs in North American Lichenology Vol. 2. Northwest Lichenologists, Corvallis, Oregon

McDaniel SF, Shaw AJ (2005) Selective sweeps and intercontinental migration in the cosmopolitan moss Ceratodon purpureus (Hedw.) Brid. Mol Ecol 87(14):1121-1132

Muñoz J, Felicísimo ÁM, Cabezas F, Burgaz AR, Martínez I (2004) Wind as a long-distance dispersal vehicle in the southern hemisphere. Science 304:1144-1147

Nejidat A, Potrafka RM, Zaady E (2016) Successional biocrust stages on dead shrub soil mounds after severe drought: effect of micro-geomorphology on microbial community structure and ecosystem recovery. Soil Biol Biochem 103:213-220

Ochoa-Hueso R, Hernandez RR, Pueyo JJ, Manrique E (2011) Spatial distribution and physiology of biological soil crusts from semi-arid Central Spain are related to soil chemistry and shrub cover. Soil Biol Biochem 43:1894-1901

Ponzetti J, McCune B (2001) Biotic soil crusts of Oregon's shrub steppe - community composition in relation to soil chemistry, climate, and livestock activity. Bryologist 104:212-225

Ponzetti J, McCune B, Pyke DA (2007) Biotic soil crusts in relation to topography, cheatgrass and fire in the Columbia Basin, Washington. Bryologist 110:706-722 
Ramcharan A, Hengl T, Nauman T, Brungard C, Waltman S, Wills S, Thompson J (2017) Soil property and class maps of the conterminous US at 100 meter spatial resolution based on a compilation of national soil point observations and machine learning arXiv preprint arXiv:1705.08323

Rayment GE, Higginson FR (1992) Australian Laboratory Handbook of Soil and Water Chemical Methods. Australian Soil and Land Survey Handbook, Vol. 3. Inkata Press, Melbourne, Australia

Reisner MD, Grace JB, Pyke DA, Doescher PS (2013) Conditions favoring Bromus tectorum dominance of endangered sagebrush steppe ecosystems. J Appl Ecol 50:1039-1049

Rodríguez-Caballero E, Aguilar MÁ, Castilla YC, Chamizo S, Aguilar FJ (2015) Swelling of biocrusts upon wetting induces changes in surface micro-topography. Soil Biol Biochem 82: 107-111

Root HT, McCune B (2012) Regional patterns of biological soil crust lichen species composition related to vegetation, soils, and climate in Oregon, USA. J Arid Environ 79:93-100

Rosentreter R, Eldridge DJ, Westberg M, Williams L, Grube M (2016) Structure, composition, and function of biocrust lichen communities. In Biological soil crusts: an organizing principle in drylands. Eds. B Weber, B Büdel, J Belnap. pp. 121-138. Springer, Berlin

Seppelt RD, Downing AJ, Deane-Coe KK, Zhang Y, Zhang J (2016) Bryophytes within biological soil crusts. In: Weber B, Büdel B, Belnap J (eds) Biological soil crusts: an organizing principle in drylands. Springer, Berlin, pp 101-120

Smith RJ (2013) Cryptic diversity in bryophyte soil-banks along a desert elevational gradient. Lindbergia 36:1-8

Soil Survey Staff, Natural Resources Conservation Service, United States Department of Agriculture. Soil Survey Geographic (SSURGO) Database for Missoula County, Montana. Available online at https://websoilsurvey.nrcs. usda.gov/. Accessed 9/1/2017
St. Clair L, Johansen J, Rushforth S (1993) Lichens of soil crust communities in the intermountain area of the western United States. The Great Basin Naturalist 53(1):5-12

Weber B, Bowker MA, Zhang Y, Belnap J (2016) Natural recovery of biological soil crusts after disturbance. In Biological soil crusts: an organizing principle in drylands. Eds. B Weber, B Büdel, J Belnap. pp. 479-498. Springer, Berlin

Wilson MF, O'Connell B, Brown C, Guinan JC, Grehan AJ (2007) Multiscale terrain analysis of multibeam bathymetry data for habitat mapping on the continental slope. Mar Geod 30:3-35

Xiao B, Hu K (2017) Moss-dominated biocrusts decrease soil moisture and result in the degradation of artificially planted shrubs under semiarid climate. Geoderma 291:47-54

Xiao B, Veste M (2017) Moss-dominated biocrusts increase soil microbial abundance and community diversity and improve soil fertility in semi-arid climates on the loess plateau of China. Appl Soil Ecol 117:165-177

Zaady E, Boeken B, Ariza C, Gutterman Y (2003) Light, temperature, and substrate effects on the germination of three Bromus species in comparison with their abundance in the field. Isr J Plant Sci 51:267-273

Zaady E, Eldridge DJ, Bowker MA (2016) Effects of local-scale disturbance on biocrusts. In Biological soil crusts: an organizing principle in drylands. Eds. B Weber, B Büdel, J Belnap. pp. 429-449. Springer, Berlin

Zhang Y, Aradottir AL, Serpe M, Boeken B (2016) Interactions of biological soil crusts with vascular plants. In Biological soil crusts: an organizing principle in drylands. Eds. B Weber, B Büdel, J Belnap. pp. 385-406. Springer, Berlin

Zhao Y, Bowker M, Zhang Y, Zaady E (2016) Enhanced recovery of biological soil crusts after disturbance. In Biological soil crusts: an organizing principle in drylands. Eds. B Weber, B Büdel, J Belnap. pp. 499-523. Springer, Berlin

Zobel M (1997) The relative of species pools in determining plant species richness: an alternative explanation of species coexistence? Trends Ecol Evol 12:266-269 